\title{
Surface Wettability of Oxygen Plasma Treated Porous Silicon
}

\author{
Lei Jiang, ${ }^{1}$ Songyan $\mathrm{Li}^{2}{ }^{2}$ Jiqian Wang, ${ }^{1}$ Limin Yang, ${ }^{1}$ Qian Sun, ${ }^{2}$ and Zhaomin $\mathrm{Li}^{2}$ \\ ${ }^{1}$ Heavy Oil State Laboratory and Center for Bioengineering and Biotechnology, China University of Petroleum (East China), \\ Qingdao 266580, China \\ ${ }^{2}$ College of Petroleum Engineering, China University of Petroleum (East China), Qingdao 266580, China
}

Correspondence should be addressed to Lei Jiang; leijiang@upc.edu.cn and Zhaomin Li; lizhm6561@163.com

Received 29 August 2013; Accepted 10 October 2013; Published 16 January 2014

Academic Editor: Marinella Striccoli

Copyright (C) 2014 Lei Jiang et al. This is an open access article distributed under the Creative Commons Attribution License, which permits unrestricted use, distribution, and reproduction in any medium, provided the original work is properly cited.

Oxygen plasma treatment on porous silicon $(\mathrm{p}-\mathrm{Si}$ ) surfaces was studied as a practical and effective means to modify wetting properties of as-fabricated p-Si surfaces, that is, contact angles of the p-Si materials. P-Si samples spanning a wide range of surface nanostructures have been fabricated which were subjected to a series of oxygen plasma treatments. Reduction of the p-Si surface contact angles has been systematically observed, and the surface activation rate constant as a function of different pore geometries has been analyzed to achieve an empirical equation. The underlying diffusion mechanisms have been discussed by taking into account of different pore diameters of p-Si samples. It is envisaged that such an approach as well as the corresponding empirical equation may be used to provide relevant process guidance in order to achieve precise control of p-Si contact angles, which is essential for many $\mathrm{p}$-Si applications especially in biosensor areas.

\section{Introduction}

The past decade has seen the rapid development of porous silicon ( $\mathrm{p}$-Si) in many applications including microelectronics, implantation, drug delivery, and biosensor [1-3] due to its distinctive properties such as large surface-area-tovolume ratio, wide range of pore geometry and morphology, biocompatibility, There has been a particular interest in the use of $\mathrm{p}$-Si for biosensors to detect biomolecular interactions and cell adhesion [4], leading to significant potentials towards applications in the fields of tissue engineering and drug delivery [5-8]. However, one of the major challenges with these applications is the precise control of surface wetting properties of $\mathrm{p}$-Si. This is particularly important as both protein and living cells are very sensitive to these wetting properties, and, when not optimized, protein or cells may either lose their bioactivity on the surface or simply resist adhering to the surface [4]. For instance, it was reported that human MG63 osteosarcoma cells tend to attach and grow only on surfaces which present the contact angle of around $64^{\circ}[9]$.

Wetting properties of $\mathrm{p}$-Si surface largely rely on surface morphology and chemical bonds [10]. While morphology is usually controlled at fabrication stage [11], surface chemical bond composition can be modified during postprocessing steps which have been the focus of many research activities. As a result, approaches using molecular grafting [12, 13], UV photosensitive molecular coating $[14,15]$, electrochemical methods [16], and so forth have been reported. However, despite some success, these reported approaches are neither efficient nor practical for the precise control of p-Si surface wetting properties. For instance, the chemical reaction conditions and the grafting density of grafted molecules may be difficult to control $[12,13]$ and the operating window may be too narrow for electrochemical method [16], let alone the costly materials for surface coating means $[14,15]$. A more practical postfabrication means is yet to be established.

Oxygen plasma treatment, a common process in semiconductor industry, has been previously used to successfully control wetting of smooth silicon wafer surface with high efficiency, controllability, and reproducibility as well as being a fast, easy-to-scale-up, and clean process [17-20]. Detailed relationship between the resultant hydrophilicity and key processing parameters has been recently studied $[19,20]$. However, to the best of our knowledge, little work has been reported to modify $\mathrm{p}$-Si surface wetting using this 
oxygen plasma treatment. As a result, there are no systematic process studies or mechanism studies in relation to these. Considering that $\mathrm{p}$-Si has distinctive surface morphologies in comparison with that of smooth $\mathrm{Si}$, it is important to study not only the effectiveness of controlled wetting in $\mathrm{p}$ Si using oxygen plasma treatment, but also the underpinning mechanism and models which can be potentially exploited for future processes.

This work reports experimental results of contact angles as a function of oxygen plasma treatments of $\mathrm{p}$-Si substrates with various surface morphologies. Surface chemical bonding modifications induced by oxygen plasma are discussed. A simple empirical model is developed to study the possible reaction kinetics on $\mathrm{p}$-Si surface with a view to establishing a first model which can be potentially exploited in applications such as biosensors and drug delivery, where precise controls of $\mathrm{p}$-Si surface wetting properties are required $[4,21,22]$.

\section{Materials and Methods}

P-Si samples were prepared by a two-electrode anodisation method using p-type $\langle 100\rangle$ Si wafers as starting substrates. Figure 1 shows a schematic of the experimental setup. The electrolyte solution consists of hydrofluoric acid (HF, 48\% $\mathrm{w} / \mathrm{w})$ and ethanol $(99.86 \% \mathrm{w} / \mathrm{w})$. By varying the key anodisation parameters such as electrolyte concentrations, current, power densities and typical p-Si samples with a range of surface morphologies (average pore size ranged from approximately $10 \mathrm{~nm}$ to $1000 \mathrm{~nm}$ ) have been obtained [23], which were then selected for the subsequent characterization and wetting studies.

The as-fabricated p-Si samples were characterized using scanning electron microscope (SEM, JSM 6500F, JEOL Ltd), and the contact angles of these p-Si samples were measured using a tensiometer (DSA 100, Kruss Ltd) with $5 \mu$ L Millipore water (18.2 $\mathrm{M} \Omega$ resistivity) based on sessile drop method [24]. At least 3 separate drops on different spots of each sample have been measured, and the average values of the contact angles were obtained. Oxygen plasma treatments were conducted using an oxygen plasma generation system (Mycro, Harrick Plasma) under a working condition of $10.5 \mathrm{~W}, 30 \mathrm{~mL} / \mathrm{min}$ oxygen flow, and 1 Torr chamber pressure. Different treatment durations were implemented. PSi samples were subjected to contact angle measurements immediately after each oxygen plasma treatment.

\section{Results and Discussion}

To study the influence of the oxygen plasma treatment, four typical as-fabricated $\mathrm{p}$-Si substrates were intentionally selected in such a way that they represent a wide range of pore diameters and surface morphologies. SEM was used to characterize the surface morphologies, as shown in Figure 2. The average pore radii are estimated to be approximately $5 \mathrm{~nm}, 25 \mathrm{~nm}, 50 \mathrm{~nm}$, and $500 \mathrm{~nm}$ for samples a, b, c, and d, respectively. These values will be used for the subsequent evaluation of contact angle changes.

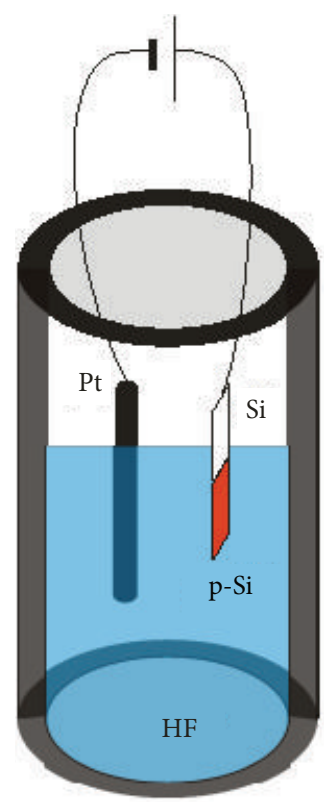

FIgURE 1: Schematic of fabrication of p-Si.

The initial contact angles of $c_{i}$ of $18^{\circ}, 36^{\circ}, 66^{\circ}$, and $138^{\circ}$ have been obtained from as-fabricated p-Si samples a, b, c and $\mathrm{d}$, respectively. It is observed that $c_{i}$ is strongly dependent on the surface morphologies where smaller contact angles correspond to smaller pore sizes. These results are in line with the previous study by Ressine et al. in that the contact angle increases as the $\mathrm{p}$-Si surface structure changes from nanoporous to macroporous [11]. The water droplet on solid surface will maintain its spherical shape in order to minimize the surface energy and reach thermodynamic equilibrium between the liquid, solid, and air phases [25]. Therefore the water contact angle is mainly determined by the chemical composition and microstructure of the solid surfaces [25]. It was well reported that the ordered pattern can affect the surface wetting, and several models such as Young, Wenzel, and Cassie models, and so forth, have been developed to numerically account for the influence of roughness on solid surface, as the p-Si used in this study $[1,11]$. The data also suggests that our $\mathrm{p}$-Si substrates represent a wide span of surface morphology and initial surface wetting properties, providing a desirable range of $\mathrm{p}$-Si samples for the subsequent wetting studies using oxygen plasma treatments.

Figure 3 shows the contact angle variation as a function of oxygen plasma treatment duration for each p-Si sample. It is observed that $\mathrm{p}$-Si contact angles can be effectively reduced by using oxygen plasma treatment even in lower power and low oxygen flow conditions as used in this work, especially at the early stage of the treatments. Extreme hydrophilicity has been observed for all the samples after $100 \mathrm{~s}$. For smooth Si surfaces, it has been reported $[20,26]$ that contact angle $c$ follows:

$$
c=c_{\infty}+\left(c_{i}-c_{\infty}\right) e^{-\varepsilon t},
$$

where $t$ is oxygen plasma treatment time duration, $c_{i}$ is the initial contact angle, $c_{\infty}$ is the final stabilized contact angle, 


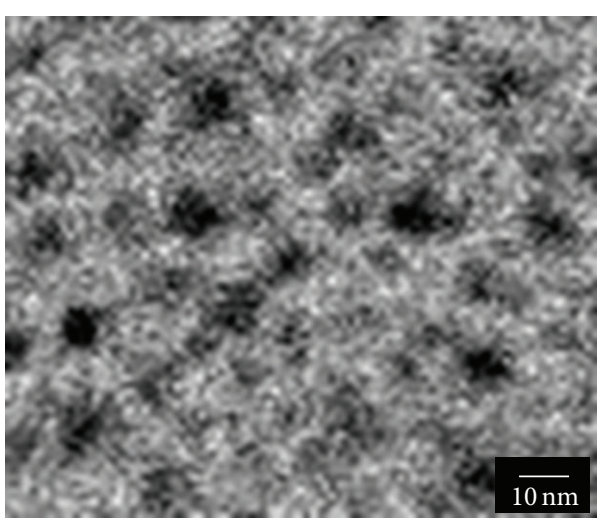

(a)

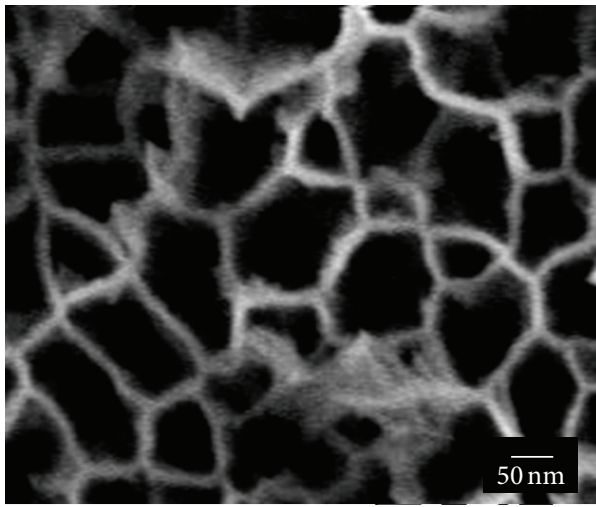

(c)

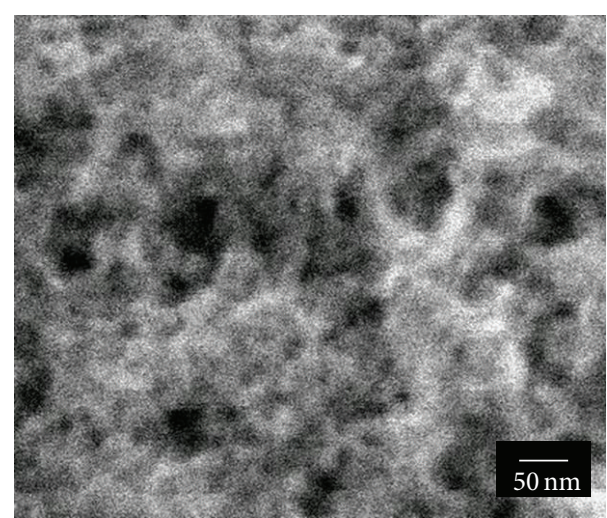

(b)

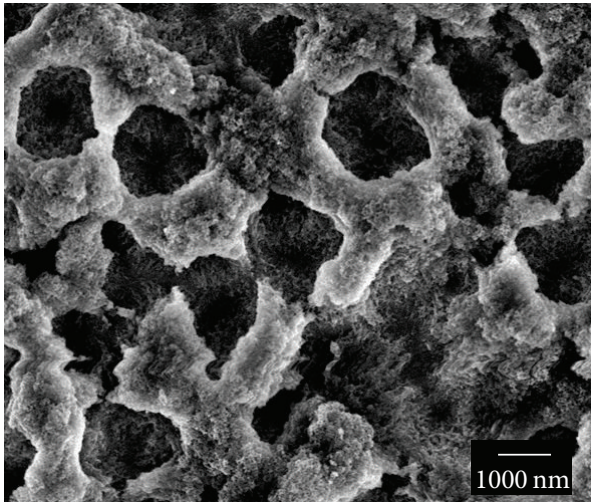

(d)

FIGURE 2: SEM images of four types of p-Si surfaces.

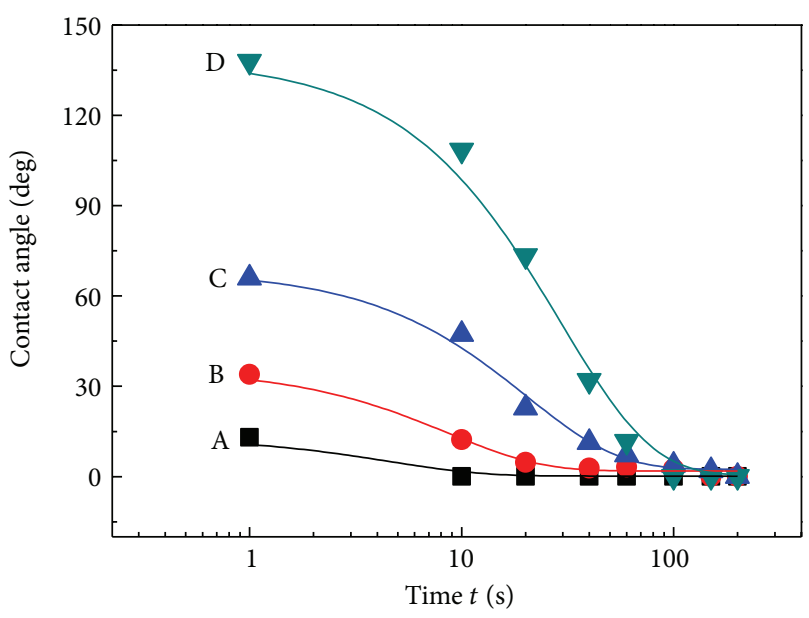

Figure 3: Dependence of contact angle at p-Si (samples A, B, C, and $\mathrm{D}$ ) surface on oxygen plasma treatment time duration. The solid lines are the best fit from (1).

and $\varepsilon$ is the surface activation rate constant [26]. Figure 3 suggests that our contact angle results can be well-fit by using (1), suggesting that, despite the distinctive morphologies difference between smooth and porous $\mathrm{Si}$, similar surface reaction mechanism may exist for both cases.
It is known that oxygen plasma induces chemical bonding modifications for Si surfaces, leading to changes of contact angles [27]. In particular, oxygen species $\left(\mathrm{O}^{*}\right)$, for example, $\mathrm{O}_{2}{ }^{-}$and $\mathrm{O}^{-}$in oxygen plasma, are first absorbed onto the $\mathrm{Si}$ surface, and then they react with the $\mathrm{Si}-\mathrm{H}$ groups on the surface to form $\mathrm{Si}-\mathrm{O}-\mathrm{Si}$ bonds, as shown in the following reaction

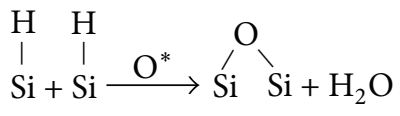

These $\mathrm{Si}-\mathrm{O}-\mathrm{Si}$ bonds spontaneously convert to polar Si$\mathrm{OH}$ bonds once in contact with water in the following contact angle measurement. These $\mathrm{Si}-\mathrm{OH}$ groups are extremely hydrophilic $[28,29]$, so we envisage that the number of polarized groups increases with the oxygen treatment duration. As a result, the whole surface appears to be extremely hydrophilic as the ultimate contact angle is below detection limit $\left(\leq 0.5^{\circ}\right)$ and this process underpins the $c$ reduction as shown in Figure 3.

Based on the fitting in Figure 3 using (1), the surface activation rate constants $\varepsilon$ can also be obtained as $0.217,0.115$, 0.050 , and $0.034 \mathrm{~s}^{-1}$ for samples $\mathrm{A}, \mathrm{B}, \mathrm{C}$, and D, respectively. Figure 4 shows $\varepsilon$ as a function of average pore radius $r$ as obtained from surface characterization with error bars. 


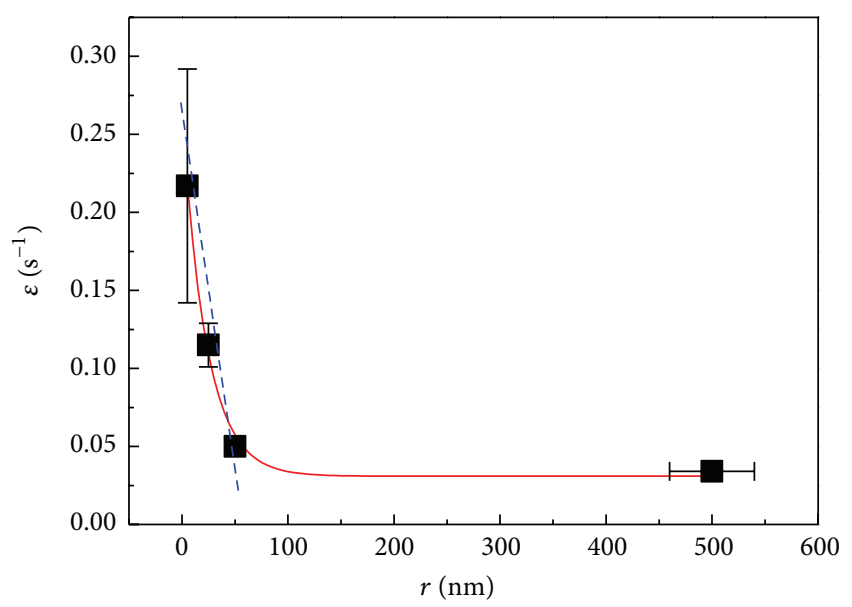

FIGURE 4: Correlation between surface activation rate constant $\varepsilon$ and the pore radius $r$ of four $\mathrm{p}$-Si samples. The solid line represents the best fit from (3). The dashed line is a guide for the eye to show the possible linear trend.

Through the best fit, an exponential equation is obtained as follows:

$$
\varepsilon=\alpha e^{\beta r}+\delta
$$

where constants $\alpha=0.233 \mathrm{~s}^{-1}, \beta=-0.043 \mathrm{~nm}^{-1}$ are $\delta=$ $0.031 \mathrm{~s}^{-1}$.

It is clear that $\varepsilon$ is strongly dependent on the pore radius of $\mathrm{p}$-Si. $\varepsilon$ is a primary constant which determines contact angle reduction rate as shown in (1). To the best of our knowledge, (3) is the first empirical equation to indicate such a relationship between $\varepsilon$ and $r$ in $\mathrm{p}$-Si. To further understand the mechanism underpinning such a relationship, we feel that it is essential to take into account the diffusion mechanisms of $\mathrm{O}^{*}$ in pore structures of the $\mathrm{p}$-Si samples, whereas such morphologies are not relevant for smooth Si surfaces. In a simplified manner, we assume that the $\mathrm{p}$-Si pores are cylindrical shapes with different pore radius $r$, as shown in Figure 5 corresponding to different $\mathrm{p}$-Si samples in this work. When the plasma conditions such as $\mathrm{O}^{*}$ flow rate and working pressure are constant, we believe that the diffusion rate of $\mathrm{O}^{*}$ to the pores are dependent on the pore radius $r$, thus leading to different $\mathrm{O}^{*}$ concentration in the pores, as indicated in Figure 5. Indeed, strong dependence of plasma reaction rates on opening pattern dimensions have been frequently observed in the fabrication of semiconductor based devices such as the aspect ratio dependent etching (ARDE) effect in deep reactive ion etching [30, 31]. As such, diffusion based mechanism such as Knudsen diffusion [32] has been widely accepted to account for such aspect ratio dependent plasma reaction phenomena [31]. Similarly in this work, it is possible that, for smaller pore dimensions, that is, $r \leq 100 \mathrm{~nm}$, Knudsen diffusion can also potentially play a role in affecting the diffusion rate and hence the concentration of $\mathrm{O}^{*}$ in the pores $\left[\mathrm{O}^{*}\right]_{\text {pore }}$, leading to the impact on reaction rate of reaction (2), as Knudsen diffusivity is linearly proportional to $r$ which seems to align with the relationship between $\varepsilon$ and $r$ when $r \leq 100 \mathrm{~nm}$, as the dotted line shows in Figure 5. However, it is also known that Knudsen diffusion underpins pore side wall collision dominant mechanism which is only suitable to be applied for small opening pores. For bigger pore openings that is over Knudsen diffusion regime, other diffusion mechanisms such as Fickian diffusion [33] and viscous flow [34] may participate in the mechanism, which deviates the effective diffusion rate from the linear correlation with $r$. As all the key plasma conditions, that is, oxygen flow rate and working pressure in this work, have been kept the same for all the plasma treatments, it is possible that is with the increase of $r$, the $\mathrm{O}^{*}$ concentration in the pores $\left[\mathrm{O}^{*}\right]_{\text {pore }}$ can potentially reach a plateau that equivalent to the $\mathrm{O}^{*}$ concentration in the chamber $\left[\mathrm{O}^{*}\right]_{\text {bulk }}$ (Figure 5 ), corresponding to a saturated $\varepsilon$ value. With largest $r$ of all the p-Si samples used in this work, sample D is likely to be within this range as also indicated in Figure 5. We acknowledge that more experiments with a large number of $\mathrm{p}$-Si samples may induce more empirical evidence that could be potentially exploited to study, in our view, the extremely complex diffusion mechanism and modeling in $\mathrm{p}$-Si samples with a vase range of morphologies. Nonetheless, these initial results as well as the empirical equation (3) provide a first approach that can be potentially used to estimate plasma treatment time durations in order to achieve precise control of the subsequent $\mathrm{p}$-Si contact angles and wetting properties. As Figure 3 shows that these contact angles are extremely sensitive to the plasma treatment durations, we envisage that such an empirical equation could be beneficial. For instance, with a set of fixed oxygen plasma conditions, by characterizing the contact angle change and surface activation rate constant $\varepsilon$ using a few $\mathrm{p}$-Si samples, a similar empirical equation (3) could be obtained with a set constants of $\alpha, \beta$, and $\delta$. With these constants which are only dependent on plasma conditions, it is possible to use (3) to estimate the related $\varepsilon$, leading to the corresponding relationship between $c$ and time $t$ in (1). This relationship between $c$ and $t$ could thus be applied to any $\mathrm{p}$-Si substrates with known pore radius $r$ which can be potentially useful for precise control of $\mathrm{p}$-Si wetting properties.

\section{Conclusions}

Effects of oxygen plasma treatment on the contact angles of p-Si substrates have been studied with a view to developing a practical and efficient postfabrication process to achieve precise control of wetting properties of $\mathrm{p}$-Si materials. PSi samples with a wide range of surface morphologies have been fabricated and characterized followed by oxygen plasma treatment in a series of time durations. The results suggest that contact angles of $\mathrm{p}$-Si are very sensitive to oxygen plasma treatments even when using a lower plasma power. It is also observed that the surface activation rate constant is strongly dependent on surface morphologies of the p-Si samples that is, pore radius. For the first time, an empirical equation was developed between the surface activation rate constants and pore radius. This can be potentially exploited to estimate relationship between contact angle and plasma treatment durations which may be beneficial towards precision control 


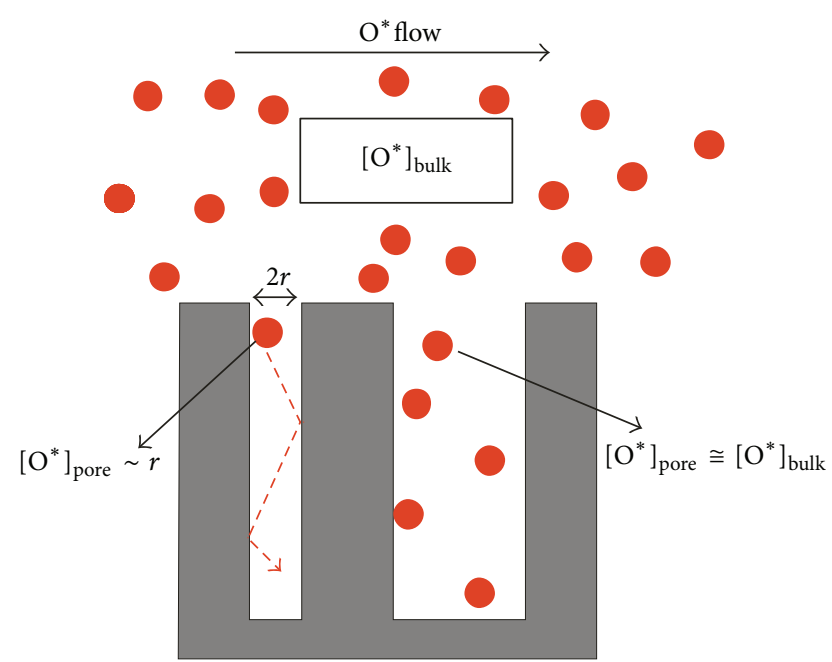

FIGURE 5: Schematic of oxygen species $\mathrm{O}^{*}$ diffusing into the pores. In the pore of small radius $r$ (left pore), the concentration of $\mathrm{O}^{*}$ inside the pore $\left[\mathrm{O}^{*}\right]_{\text {pore }}$ is dependent on $r$ due to collision with pore walls based on Knudsen model, while for pore size of sufficiently large $r$ (right pore), $\left[\mathrm{O}^{*}\right]_{\text {pore }}$ is almost equal to the bulk $\mathrm{O}^{*}$ concentration in the chamber $\left[\mathrm{O}^{*}\right]_{\text {bulk }}$.

of $\mathrm{p}$-Si contact angles. Possible diffusion mechanisms in relation to the variation of pore radius are discussed aligning with the empirical results.

\section{Conflict of Interests}

The authors declare that there is no conflict of interests regarding the publication of this paper.

\section{References}

[1] H. Föll, M. Christophersen, J. Carstensen, and G. Hasse, "Formation and application of porous silicon," Materials Science and Engineering R: Reports, vol. 39, no. 4, pp. 93-141, 2002.

[2] E. J. Anglin, L. Cheng, W. R. Freeman, and M. J. Sailor, "Porous silicon in drug delivery devices and materials," Advanced Drug Delivery Reviews, vol. 60, no. 11, pp. 1266-1277, 2008.

[3] M. Latterich and J. Corbeil, "Label-free detection of biomolecular interactions in real time with a nano-porous silicon-based detection method," Proteome Science, vol. 6, article 31, 2008.

[4] S. D. Alvarez, A. M. Derfus, M. P. Schwartz, S. N. Bhatia, and M. J. Sailor, "The compatibility of hepatocytes with chemically modified porous silicon with reference to in vitro biosensors," Biomaterials, vol. 30, no. 1, pp. 26-34, 2009.

[5] N. Massad-Ivanir, G. Shtenberg, A. Tzur, M. A. Krepker, and E. Segal, "Engineering nanostructured porous $\mathrm{SiO}_{2}$ surfaces for bacteria detection via "Direct Cell Capture'”, Analytical Chemistry, vol. 83, no. 9, pp. 3282-3289, 2011.

[6] S. P. Low, K. A. Williams, L. T. Canham, and N. H. Voelcker, "Evaluation of mammalian cell adhesion on surface-modified porous silicon," Biomaterials, vol. 27, no. 26, pp. 4538-4546, 2006.

[7] L. M. Bonanno and E. Segal, "Nanostructured porous siliconpolymer-based hybrids: from biosensing to drug delivery," Nanomedicine, vol. 6, no. 10, pp. 1755-1770, 2011.
[8] M. M. Orosco, C. Pacholski, G. M. Miskelly, and M. J. Sailor, "Protein-coated porous-silicon photonic crystals for amplified optical detection of protease activity," Advanced Materials, vol. 18, no. 11, pp. 1393-1396, 2006.

[9] D. P. Dowling, I. S. Miller, M. Ardhaoui, and W. M. Gallagher, "Effect of surface wettability and topography on the adhesion of osteosarcoma cells on plasma-modified polystyrene," Journal of Biomaterials Applications, vol. 26, no. 3, pp. 327-347, 2011.

[10] J. Dong, Z. Yao, T. Yang, L. Jiang, and C. Shen, "Control of superhydrophilic and superhydrophobic graphene interface," Scientific Reports, vol. 3, article 1733, 2013.

[11] A. Ressine, D. Finnskog, G. Marko-Varga, and T. Laurell, "Superhydrophobic properties of nanostructuredmicrostructured porous silicon for improved surface-based bioanalysis," Nanobiotechnology, vol. 4, no. 1-4, pp. 18-27, 2008.

[12] S. Pace, P. Gonzalez, J.-M. Devoisselle, P.-E. Milhiet, D. Brunel, and F. Cunin, "Grafting of monoglyceride molecules for the design of hydrophilic and stable porous silicon surfaces," New Journal of Chemistry, vol. 34, no. 1, pp. 29-33, 2010.

[13] L. Fernández, M. Sánchez, F. J. Carmona et al., "Analysis of the grafting process of PVP on a silicon surface by AFM and contact angle," Langmuir, vol. 27, no. 18, pp. 11636-11649, 2011.

[14] D. Dattilo, L. Armelao, G. Fois, G. Mistura, and M. Maggini, "Wetting properties of flat and porous silicon surfaces coated with a spiropyran," Langmuir, vol. 23, no. 26, pp. 12945-12950, 2007.

[15] D. Dattilo, L. Armelao, M. Maggini, G. Fois, and G. Mistura, "Wetting behavior of porous silicon surfaces functionalized with a fulleropyrrolidine," Langmuir, vol. 22, no. 21, pp. 87648769, 2006.

[16] Z. Wang and N. Koratkar, "Electrically controlled wetting and dewetting transition on silicon micro-pillar arrays," Advanced Science Letters, vol. 1, no. 2, pp. 222-225, 2008.

[17] B. A. Langowski and K. E. Uhrich, "Oxygen plasma-treatment effects on Si transfer," Langmuir, vol. 21, no. 14, pp. 6366-6372, 2005.

[18] S.-W. Choi, W.-B. Choi, Y.-H. Lee, B.-K. Ju, M.-Y. Sung, and B.-H. Kim, "The analysis of oxygen plasma pretreatment for improving anodic bonding," Journal of the Electrochemical Society, vol. 149, no. 1, pp. G8-G11, 2002.

[19] L. Jiang, Z. Li, L. Yang et al., "Effect of oxygen plasma on surface wettability of porous silicon," China Surface Engineering, vol. 26, no. 5, pp. 43-48, 2013.

[20] S. B. Habib, E. Gonzalez, and R. F. Hicks, "Atmospheric oxygen plasma activation of silicon (100) surfaces," Journal of Vacuum Science and Technology A, vol. 28, no. 3, pp. 476-485, 2010.

[21] A. M. Rossi, L. Wang, V. Reipa, and T. E. Murphy, "Porous silicon biosensor for detection of viruses," Biosensors and Bioelectronics, vol. 23, no. 5, pp. 741-745, 2007.

[22] N. Naveas, V. T. Costa, D. Gallach et al., "Chemical stabilization of porous silicon for enhanced biofunctionalization with immunoglobulin," Science and Technology of Advanced Materials, vol. 13, no. 4, Article ID 045009, 2012.

[23] M. J. Sailor, "Fundamentals of porous silicon preparation," in Porous Silicon in Practice, pp. 1-42, Wiley-VCH Verlag GmbH \& Co. KGaA, 2011.

[24] Z. W. A, "Relation of the equilibrium contact angle to liquid and solid constitution," in Contact Angle, Wettability, and Adhesion, pp. 1-51, American Chemical Society, 1964.

[25] J. N. Israelachvili, Intermolecular and Surface Forces, Academic Press, London, UK, 2nd edition, 1992. 
[26] E. Gonzalez II, M. D. Barankin, P. C. Guschl, and R. F. Hicks, "Remote atmospheric-pressure plasma activation of the surfaces of polyethylene terephthalate and polyethylene naphthalate," Langmuir, vol. 24, no. 21, pp. 12636-12643, 2008.

[27] T. Suni, K. Henttinen, I. Suni, and J. Mäkinen, "Effects of plasma activation on hydrophilic bonding of $\mathrm{Si}$ and $\mathrm{SiO}_{2}$," Journal of the Electrochemical Society, vol. 149, no. 6, pp. G348-G351, 2002.

[28] A. Grabbe, T. A. Michalske, and W. L. Smith, "Strained siloxane rings on the surface on silica. Their reaction with organosiloxanes, organosilanes, and water," Journal of Physical Chemistry, vol. 99, no. 13, pp. 4648-4654, 1995.

[29] Y. J. Chabal, Fundamental Aspects of Silicon Oxidation, Springer, Berlin, Germany, 2001.

[30] R. A. Gottscho, C. W. Jurgensen, and D. J. Vitkavage, "Microscopic uniformity in plasma etching," Journal of Vacuum Science \& Technology B, vol. 10, pp. 2133-2147, 1992.

[31] J. Yeom, Y. Wu, J. C. Selby, and M. A. Shannon, "Maximum achievable aspect ratio in deep reactive ion etching of silicon due to aspect ratio dependent transport and the microloading effect," Journal of Vacuum Science and Technology B, vol. 23, no. 6, pp. 2319-2329, 2005.

[32] K. Malek and M.-O. Coppens, "Knudsen self- and Fickian diffusion in rough nanoporous media," Journal of Chemical Physics, vol. 119, no. 5, pp. 2801-2811, 2003.

[33] B. Hosticka, P. M. Norris, J. S. Brenizer, and C. E. Daitch, "Gas flow through aerogels," Journal of Non-Crystalline Solids, vol. 225, no. 1-3, pp. 293-297, 1998.

[34] J. S. Andrade Jr., U. M. S. Costa, M. P. Almeida, H. A. Makse, and H. E. Stanley, "Inertial effects on fluid flow through disordered porous media," Physical Review Letters, vol. 82, no. 26, pp. 52495252, 1999. 

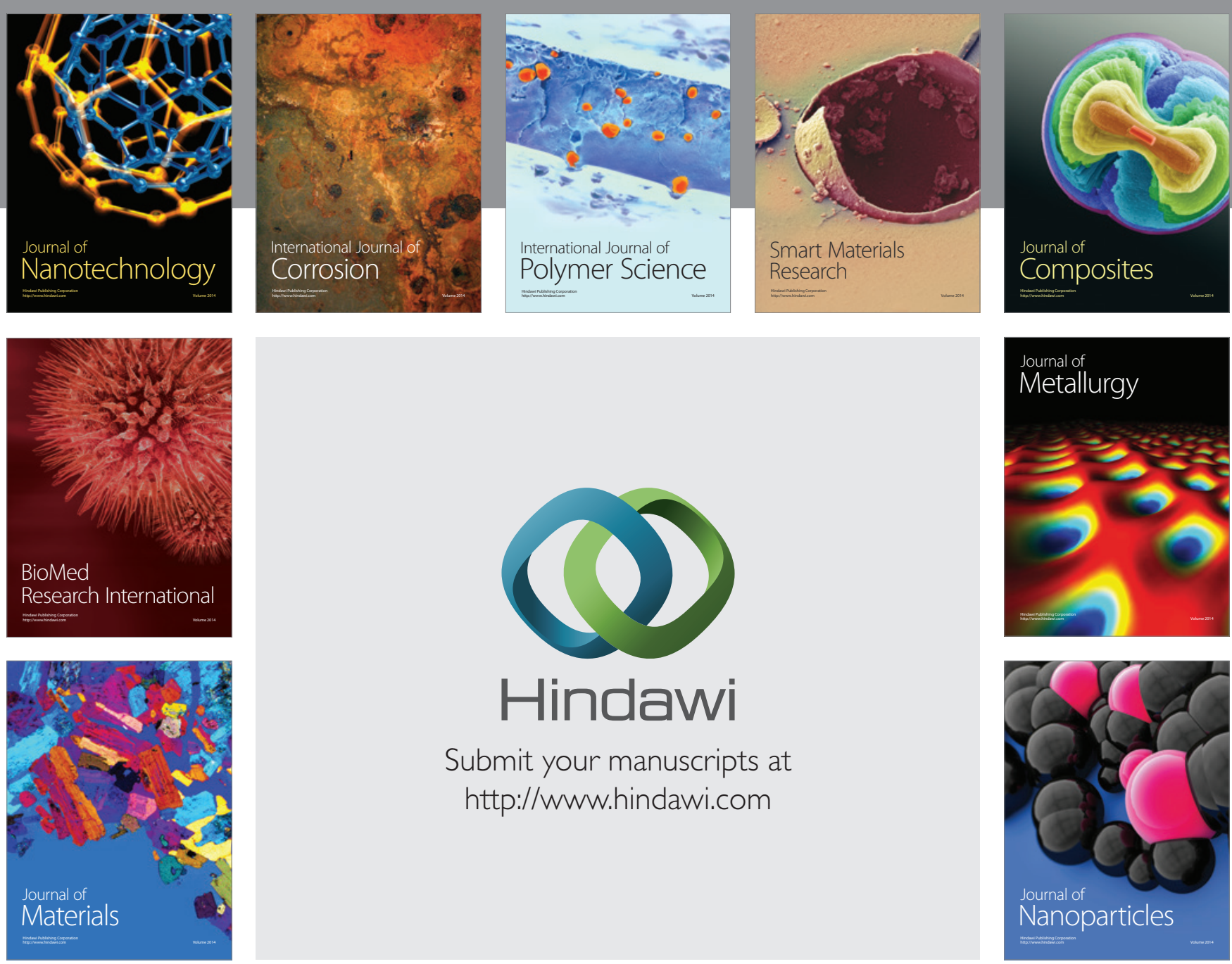

Submit your manuscripts at http://www.hindawi.com
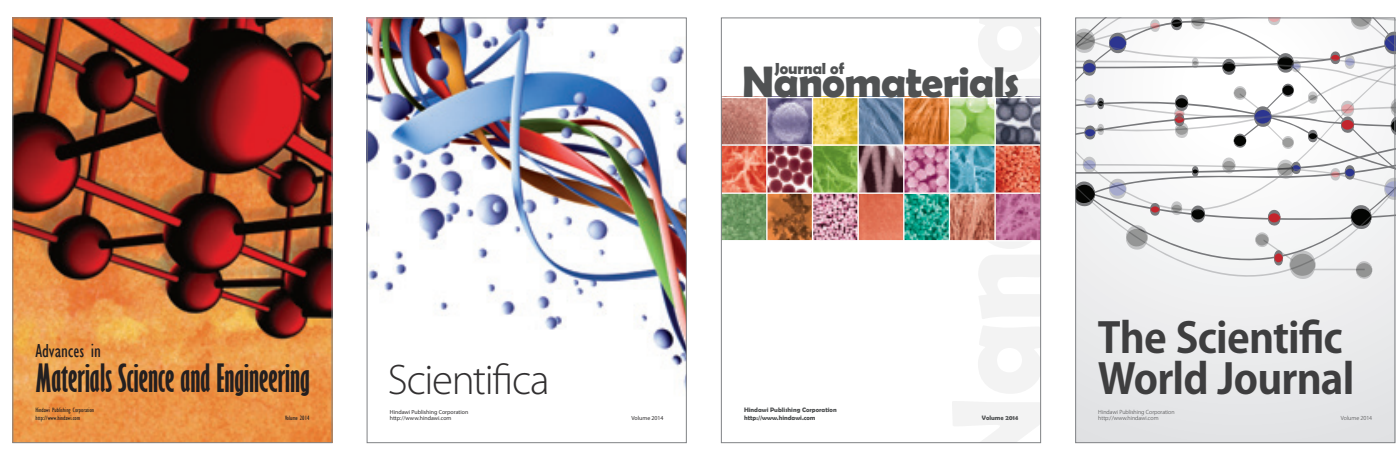

\section{The Scientific World Journal}
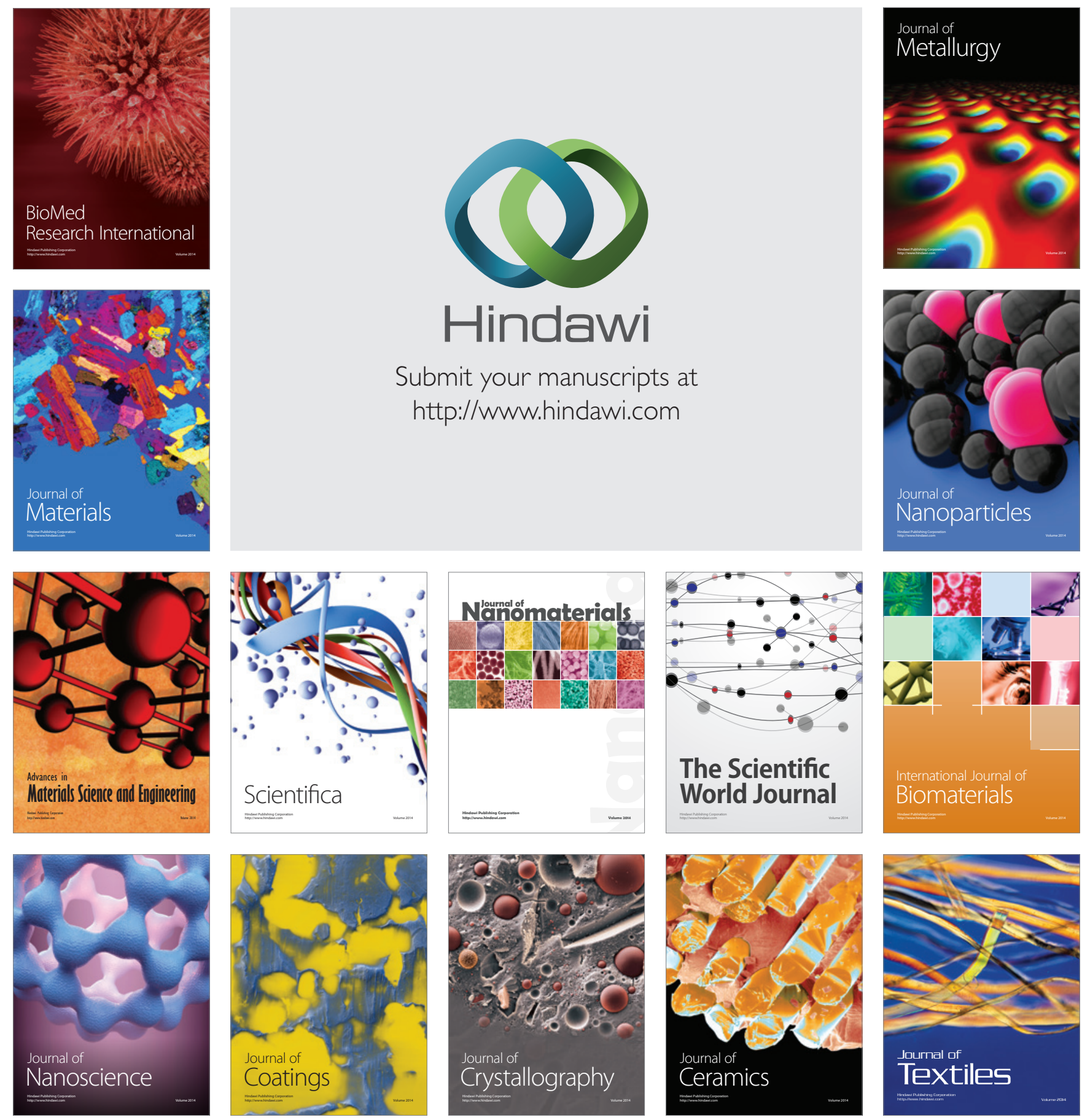